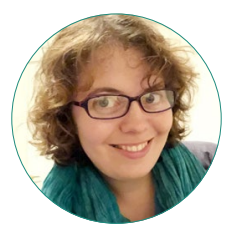

В.Н. Мерзлякова

\title{
CELEBRITY CULTURE В СИСТЕME СОВРЕМЕННЫХ КУЛЬТУРНЫХ ИНДУСТРИЙ: ОСОБЕННОСТИ ПРОИЗВОДСТВА ПУБЛИЧНОСТИ В СТРУКТУРЕ НОВЫХ МЕДИА
}

\section{Правильная ссылка на статью:}

Мерзлякова В.H. Celebrity culture в системе современных культурных индустрий: особенности производства публичности в структуре новых медиа // Мониторинг общественного мнения: экономические и социальные перемены. 2021. № 5. C. 47-63. https:// doi.org/10.14515/monitoring.2021.5.2008.

\section{For citation:}

Merzliakova V. N. (2021) Celebrity Culture in the System of Modern Cultural Industries: Features of Publicity Production in the Structure of New Media. Monitoring of Public Opinion: Economic and Social Changes. No. 5. P. 47-63. https://doi.org/10.14515/monitoring.2021.5.2008. (In Russ.) 
CELEBRITY CULTURE B CИCTEME COВРЕМЕННЫХ КУЛЬТУРНЫХ ИНДУСТРИЙ: ОСОБЕННОСТИ ПРОИЗВОДСТВА ПУБЛИЧНОСТИ В СТРУКТУРЕ НОВЫХ МЕДИА

МЕРЗЛЯКОВА Виктория Николаевна - кандидат культурологии, доцент факультета культурологии, Российский государственный гуманитарный университет, Москва, Россия; доцент Школы актуальных гуманитарных исследований, Российская академия народного хозяйства и государственной службы, Москва, Россия

E-MAIL:vmerzliacova@yandex.ru https://orcid.org/0000-0002-6458-0812

Аннотация. Статья посвящена тому, как культура селебрити вписывается в поле культурных индустрий и развивает принципы конвертации различных форм капитала (финансового, социального, культурного). Социальные медиа трансформируют саму идею селебрити, открывая путь для развития публичного позиционирования новых участников. Особый интерес представляют изменения, включающие в круг селебрити тех, кто раньше был в роли участника "из-за кулис" - обеспечивал процесс развития проекта, но выполнял технические и закадровые функции. Появление таких сценариев создает предпосылки для повышения потенциала трансмедийного повествования в развитии проектов в сфере культуры. Так как новая культура селебрити включает также участников, которые раньше (до поворота веб 2.0 технологий) не воспринимались как участники публичного поля, массовой культуры. Сегодня специалисты разных направлений и областей знаний используют алгоритмы развития профессиональ-
CELEBRITY CULTURE IN THE SYSTEM OF MODERN CULTURAL INDUSTRIES: FEATURES OF PUBLICITY PRODUCTION IN THE STRUCTURE OF NEW MEDIA

Viktoriia N. MERZLIAKOVA ${ }^{1,2}$ - Cand. Sci. (Cultural studies), Associate Professor at the Department of Cultural studies; Associate Professor of the School for Contemporary Reserach in Humanities E-MAIL:vmerzliacova@yandex.ru https://orcid.org/0000-0002-6458-0812

\footnotetext{
${ }^{1}$ Russian State University for the Humanities, Moscow, Russia

2 Russian Presidential Academy of National Economy and Public Administration, Moscow, Russia
}

Abstract. The article focuses on how the culture of celebrity fits into the field of cultural industries and develops the principles of converting various forms of capital (financial, social, cultural). Social media transforms the very idea of celebrity, paving the way for the development of public positioning of new entrants. We pay special attention to changes which include in the circle of celebrities those who were previously in the role of a participant "from behind the scenes" although they ensured the process of project development, they performed technical and offscreen functions. The emergence of such scenarios creates the preconditions for increasing the potential of transmedia storytelling in the development of cultural projects. Since the new culture of celebrity also includes those who previously (before the turn of web 2.0 technologies) were not perceived as participants in the public field and mass culture. Today, specialists use algorithms for the development of the professional role of a "celebrity" in PR. "Celebrity" is no longer a concept exclusively for 
ной роли "знаменитости" в пиар-деятельности. "Селебрити" больше не является понятием исключительно мира шоу-бизнеса и позволяет говорить об универсальных принципах создания публичной фигуры успешного лидера в различных индустриях и сферах коммуникации. В статье обсуждается, как селебрити-технологии включены в развитие аккаунтов социальных сетей специалистов помогающих профессий: преподавателей, психологов, докторов.

Ключевые слова: селебрити, культура звезд, культурные индустрии, персональный бренд, новые медиа, шоубизнес, профессиональная репутация show business. It is about the universal principles of creating a public figure of a successful leader in different areas. The article discusses how the principles of celebrity as a technology are included in the development of social media for specialists in helping professions: teachers, psychologists, doctors.

Keywords: celebrity studies, stardom, cultural industries, personal branding, professional reputation, new media, show business

Роль публичных персон в формировании повседневных взглядов обывателей, развитии рекламы, массовой культуре на протяжении XX-XXI веков неуклонно росла. Актеры и музыканты, политики и общественные деятели, художники, телевизионные ведущие, спортсмены, дизайнеры одежды-вот далеко не полный список ролевых разновидностей “звезд", жизнь которых оказывалась в фокусе пристального общественного внимания. При этом, говоря об известных людях как о некотором общем явлении и определенном социокультурном типаже, мы говорим одновременно и о тех медиатехнологиях, благодаря которым аудитория узнает о персоне и может вступить с ней в какое-то взаимодействие. С развитием социальных сетей и усовершенствованием техники для съемок, появлением разнообразных инструментов редакции и коррекции фото и видео существенно расширился диапазон ролей и образов тех, кто претендует на роль селебрити.

Прежде всего необходимо сказать несколько слов о ключевых терминах, часто понимаемых либо слишком однородно, либо слишком яростно противопоставляемых: лидеры мнений, звезды, знаменитости - более-менее давно прижившиеся в русском языке, а вот селебрити и инфлюенсеры закрепились в русскоязычной транскрипции относительно недавно. Все эти слова относятся к ряду близких понятий, обозначающих тех, кто оказывает влияние на окружающих и обладает публичным статусом, чем-то прославился. Они различаются больше на уровне традиций и школ изучения, но часто понимаются близко в естественном языке. Тем не менее для дальнейших рассуждений требуется ряд пояснений и оговорок. Последние два термина получили широкое распространение в 2000-е годы, с развитием цифровых технологий, новых медиа и социальных сетей. "Селебрити" отсылает читателя не просто к привычному синониму слова "знаменитость", но и к целому направлению академических исследований феномена и его социокультурных эффектов — celebrity studies [Austin, Barker, 2003; Giles, 2018]. А термин «инфлюен- 
сер" закрепился главным образом благодаря развитию цифровой экономики, где "влияющий" (от англ. influence - влиять) стал одним из ключевых агентов рынка. Инфлюенсер - лидер мнений, активно развивающий собственный персональный бренд (зачастую благодаря аккаунту в соцсетях), обладающий большой активной аудиторией, способный влиять на ее решения и желания. Упомянутое понятие "лидеры мнения" отсылает к социологической традиции изучения влияния авторитетов на формирование мнений аудитории, берущей начало в середине 1940-х годов с работ П. Лазарсфельда [Lazarsfeld, Berelson, Gaudet, 1944]. Испанский философ Х. Ортега-и-Гассет характеризовал "знаменитость", как человека, непременно совершившего знаменательный поступок. В его трактовке понятие знаменитости близко понятию знатности, и фактически одно определяет другое, создавая логичную последовательность, распределение привилегий в обществе. «Знатный означает знаменитый, известный всему свету, тот, кого известность и слава выделили из безымянной массы. Имеются в виду те исключительные усилия, которым обязана слава" [Ортега-и-Гассет, 2002: 62]. Дальше речь идет о непременной связи такого рода усилий с подвигом, который могут оценить остальные члены сообщества, а затем оказать прославившемуся знаки признания и почести. Однако со временем древняя связка между известностью и подвигом заменяется просто фактом известности для большой аудитории - вместе с развитием массового общества в XX веке, средств массовой коммуникации и популярной культурой. Параллельно с этими тенденциями развивается и понятие "звездность", получившее распространение вместе с "желтой прессой", жанром сплетен о знаменитых людях, развитием кинематографа в первой половине XX века [Evans, 2005: 23-25]. Метафора, лежащая в основе образа звезды, предполагает соблюдение двух основных факторов - недосягаемости персоны, чьи проявления частной жизни не менее интересны публике, чем "знаменательные поступки" и яркое свечение, привлекающее внимание, контрастно выделяющее звезду, заставляющее следить за ней, не отрывая взгляда.

Одним из важных феноменов селебрити цифровой эпохи 2000-х стало появление так называемых микроселебрити. Феномену посвящена большая монография американской исследовательницы коммуникации и культуры знаменитостей в сети Элис Марвик [Marwick, 2013]. Принципиальное отличие от классической системы звезд (именно системы отношений и взаимодействий, в которые включены не только сами знаменитости, но и медиаиндустрия, обеспечивающая "сияние", продюсеры, формирующие интерес аудитории, и другие участники) в эпоху новых медиа социальных сетей заключается в расширении жизненных сценариев и профессиональных ниш, в которых возможно говорить о феномене селебрити. Микроселебрити - феномен развития локальных предложений персонального позиционирования.

Если взять за основу определения селебрити такие категории, как видимость действий для наблюдения и порождения обсуждений (сплетен), большая аудитория, освещение профессионального и личного аспектов повседневности, трансляция определенных клише реакций и образа жизни, появление специфических коммуникативных практик, таких как интервью, встречи с поклонниками, ответы на вопросы,- все эти атрибуты известности стали доступны практически любому 
пользователю сети как инструменты, использование которых в определенных последовательностях и алгоритмах производит публичность. При этом важно, что публичность и внимание аудитории могут быть обеспечены не только после совершения знаменательных поступков, но и вне иерархии значимости производимых действий. Фактически статус знаменитости сегодня может быть получен при правильной последовательности действий (таких как многочисленные приемы активации аудитории, работа с информационными трендами, наращивание аудитории рекламными кампаниями), удачном стечении обстоятельств и при том, что применительно к секрету хитов в музыкальной индустрии Джон Сибрук называет "крючком" (hook) [Сибрук, 2016: 5-15] - найденной резонирующей, часто виральной особенности производимого контента. Виральность контента, то есть готовность зрителей самостоятельно распространять материал, делясь друг с другом, является сегодня одним из важнейших инструментов продвижения персоны.

Теория конвертации и взаимного приумножения культурного, социального и финансового капитала, описанная еще в 1980-е годы Пьером Бурдье [Бурдье, 2002], помогает понять механику, во многом определяющую принципы современной символической экономики. "Возможность конвертации различных типов капитала служит основой стратегий, направленной на обеспечение воспроизводства капитала (и позиции, занимаемой его обладателем в социальном пространстве)" [там же: 72]. Известность перестала быть усиливающим следствием совершенного ранее действия (сыгранной роли, исполненной песни и т. д.), но стала принципом производства смысла и ценности продукта культурных индустрий. Реализация определенного алгоритма действий в социальных сетях позволяет производить и размещать материал, становится популярным даже без изначального знаменательного события.

В статье речь пойдет о том, как изменившийся с развитием социальных сетей медийный ландшафт трансформировал не только способы взаимодействия публичных персон с аудиторией, но и сами границы культурного поля. Это привело к изменению объема понятия "селебрити" и представлений о том, кто может стать знаменитым и интересным публике. Практики публичности сегодня меняют принципы развития современных культурных индустрий, дают потенциал для развития трансмедийного повествования отдельных проектов, а также вовлекают в орбиту "звездности" новые не просто типажи и роли селебрити, но области и сферы занятости. В дальнейшем тексте мы будем использовать понятия "знаменитости", "селебрити" и "звезды" как близкие по значению, поскольку нас в данном случае интересуют скорее принципы производства публичности, чем лингвистические особенности употребления слов в русском языке (что является не менее важной, но отдельной задачей).

Следуя ставшей классической формуле Маршалла Маклюэна о связи технологии и сообщения - "средство коммуникации есть сообщение" [Маклюэн, 2003], важно замечать, как элементы медиасреды пересобирают принципы организации культурных индустрий: появляются новые площадки представления продукции, новые игроки рынка вступают в конкуренцию, создаются новые условия порождения дискурса. Это приводит нас ко второму наблюдению о расширении границ видимости культурной индустрии, когда в поле зрительского интереса и внимания 
попадают те участники производства, которые до того были в тени главных героев. И если в 1990-е годы на публичную арену музыкального бизнеса вышли не только артисты и исполнители, но и ведущие продюсеры, то 2010-е зрительский интерес обратился в том числе к персонам закулисья - звукорежиссерам, фотографам, художникам по свету и другим профессионалам мира шоу-бизнеса. Все они получили возможность рассказать свои истории и показать свою оптику видения процесса, добавив полифоничности среде и, в случае успеха - статуса себе. Такого рода поворот и смещение фокуса с перформеров (тех, кто представляет проект) на специалистов, обеспечивающих отдельные сферы его существования, имеет целый ряд важных последствий для развития индустрий и логики продвижения продуктов. Также важно отметить, как принципы подачи информации меняют правила и создают культуру “звезд" в новых областях, до недавнего времени не ассоциировавшихся со сферами развития культуры селебрити - фактически селебрити становится скорее одним из жанров производства и представления контента, стиля коммуникации, работы в поле дискурса "звездности". Поле действия принципов культуры селебрити расширяется от сфер шоу-бизнеса и персонажей, раскручиваемых классическими медиа (телевидением, прессой, радио), к самому широкому кругу ранее непубличных профессий. Теперь от понимания принципов позиционирования себя “звездой" зависит успех в привлечении аудитории и поиске клиентуры. Например, сюда относятся разные области экспертности, представители помогающих профессий - доктора, психологи, репетиторы и др. Мы постараемся взглянуть на понятие “селебрити" с точки зрения ключевых принципов, организующих коммуникацию героя и аудитории и репрезентацию персонального образа.

\section{Система “звезд" и культурные индустрии в медиа}

Термин “культурные индустрии" вошел в академический оборот с конца 1940-х годов благодаря программному тексту Теодора Адорно и Макса Хоркхаймера, посвященному изменениям в производстве культурной продукции в массовой культуре XX века [Адорно, Хоркхаймер, 2016]. Для авторов понятие культурной индустрии носит во многом оценочный характер и является метафорой бездушного конвейерного производства, девальвирующего глубину смыслов и сложность культурных текстов. При этом именно в "Культурной индустрии" был описан ряд важных принципов развития и представления продукции (серийность, общие шаблоны, ориентированность на быстрое потребление и др.), которые работают и сегодня. Термин был подхвачен и получил развитие в программах развития культурной политики ряда европейских стран в 1980-е годы, уходя от оценочности и критики, приобретая все больше конструктивных черт описания новой среды производства контента, создания дополнительных рабочих мест, повышения доступности самих продуктов культуры для более широкой аудитории. "Термин „культурная индустрия“ несет в себе идею экономической способности культурного производства создавать продукт, занятость и доходы и удовлетворять запросы потребителей» [Тросби, 2013].

Сегодня существует несколько актуальных концепций и близких областей, которые могут быть обозначены как культурные индустрии, креативные индуст- 
рии и когнитивные индустрии, при этом между ними существует не только общее, но и сильные противоречия (Подробнее о развитии этих понятий, общих идеях и противоречиях в подходах см. [Хестанов, 2018]). Однако нам необходимо сфокусироваться на нескольких чертах культурных индустрий, которые важны для понимания принципов развития культуры знаменитостей. Во-первых, говоря о культурных индустриях, мы как бы переключаемся в экономический режим понимания культуры как сферы, производящей продукцию, обладающую определенной символической ценностью (подробнее о системе культурных ценностей cм. [Banks, 2019]), которая может быть в несколько шагов переведена в финансовые показатели успеха. В России поворот к коммерчески успешной популярной культуре, действующей в условиях конкуренции за зрительское внимание, произошел в 1990-е годы. Запрос на коммерческий успех проектов популярной культуры мы видим в новых словах того времени: "бестселлер", "шоу-бизнес", «продюсер", "хит" и др.

Этот период стал временем складывания новой системы звезд, освоения приемов репрезентации звездной жизни и персонального брендинга. К официальным званиям заслуженных и народных артистов добавились известные публике, но неофициальные "титулы" - король эстрады, золотой голос (саксофон, гитара и др.), примадонна, императрица и т. д. Сборные концерты перестали быть чередой отдельных номеров, но выстраивали для зрителя иллюзию погружения в мир семейных и дружеских отношений артистов. Например, позволяли следить за романтическими отношениями Аллы Пугачевой и Филиппа Киркорова, чья свадьба и венчание стали примером образцовой медиарепрезентации превращения частной жизни в достояние публики. Перипетии крушения этого союза и сложное выстраивание новой конфигурации семейных отношений "примадонны российской эстрады" (Аллы Пугачевой) стали достоянием "желтой прессы», были зафиксированы в клипах, концертных постановках, телевизионных программах - на этом примере мы можем наблюдать переплетение и взаимное проникновение элементов частной жизни и художественных образов и текстов. Погруженный в реальность телевизионного и глянцевого мира зритель знал расстановку отношений дружественности и конкуренции, любви и ненависти между звездами. На телевидении этого периода активно осваивались форматы американского и европейского популярного TV. Так в обиход повседневности зрителя вошли откровенные интервью о превратностях частной жизни звезд в духе "Шоу Опры Уинфри", фильмы о частной жизни, светская хроника, экскурсии по домам знаменитостей, реалити-шоу с участием звезд (например, мировая франшиза телешоу «Последний герой» о выживании на необитаемом острове, показанная на "Первом канале" с участием российских звезд эстрады в 2001 г.) и другие ставшие классическими форматы. Позже, уже в начале 2000-х, телевизионные продюсеры, понимая необходимость расширения количества актуальных для зрителя имен и необходимость вносить разнообразие в сетку вещания, поставили на поток специальные шоу, в задачи которых входило создание новых знаменитостей. Образцовым примером такого жанра, объединившим реалити-шоу с музыкальной концертной программой, стала серия "Фабрика звезд", в своем названии (да и сути) подхватывающая все ключевые тезисы программной критики Адорно и Хоркхаймера. 
Если пробежаться по журналистским клише, обозначающим знаменитостей: человек из телевизора, лицо с обложки, персонаж глянца или желтой прессы, герой с плаката, - мы видим, что в каждом из них содержится указание на медиа, благодаря которым аудитория узнает и взаимодействует с героем. У каждого медиа своя пропускная способность, свой ресурс эффективности и аудиторного охвата. Пресса, радио и телевидение - три кита, обеспечивавшие развитие культуры "звезд" и продвигавшие продукты культурных индустрий в XX веке. Ограниченное число участников попадали в систему тиражирования и становились объектами повестки дня. Система классической медийной поддержки обеспечивала массовую аудиторию, внимание к одним и тем же событиям и визуальным образам, поводам для обсуждения и пересудов. Усилия медиаменеджеров по продвижению артистов и их личностей охотно подхватывались самими зрителями. Как объясняет феномен востребованности дискурса звезд и обсуждения публичных персон профессор Дэвид Маршалл, эксперт по медиакоммуникациям, одна из ключевых задач "звезд" для обывателей состоит в том, чтобы "обучать целые поколения тому, как стать частью культуры потребления и использовать ее, чтобы „делать“ себя" [Маршалл, 2016: 139]. Распространение слухов и сплетен об известных людях, с одной стороны, безопаснее, нежели обсуждение реальных знакомых (едва ли будет иметь значимые последствия для говорящих), с другой стороны, обеспечивает непрерывность дискурса, повышает эмоциональную вовлеченность в массовую культуру.

Развитие новых медиа и социальных сетей в 2000-е годы изменило соотношение сил и расстановку игроков на поле битвы за известность. Логика производства селебрити предполагала, что медиаподдержка сама по себе обеспечивает фигуру вниманием аудитории и является подтверждением значимости. Однако принципы технологий веб 2.0 ${ }^{1}$, открывшие пользователям фактически равный технологический доступ к публичному представлению себя, в корне перестроили логику конкуренции за известность. Изменилась последовательность, предполагавшая вначале действие, вызывающее интерес публики (или хотя бы многократная демонстрация готовой продукции - клипа, фильма и т.д.), а потом закрепление и фиксацию образа персоны в медиа в личном плане, планомерное построение бренда через постепенное усиление присутствия на телевидении, радио, в прессе. Теперь представить себя в медиа, причем условно бесплатно, может практически любой пользователь. Сделать свою жизнь, перемещения, отношения, приемы пищи и прочие бытовые детали видимыми, а мнения - слышимыми. Меняется логика конкуренции - от ограниченного ресурса трансляции к ограниченному ресурсу внимания. Медиапредставленность перестает быть обещанием значимости и становится лишь точкой входа на ярмарку предложений. Регистрация в соцсети дает пользователю не только аккаунт, но и первый статус блогера. Достаточен ли он для капитализации своего присутствия? Если рассматривать подход культурных индустрий как оптику превращения образа или мнения в продукт, а коммуникативную площадку - в место продажи, мы видим, как буквально каждая деталь технологии, придуманная для расширения персонального присутствия и «честной

\footnotetext{
1 См.: О'Рейли Т. Что такое Веб 2.0 // Компьютерра. 2005. 18 октября. URL: https://old.computerra.ru/think/234100/ (дата обращения: 30.10.2021).
} 
коммуникации", превращается в инструмент продвижения и продажи. Так, пользователи ставят геолокации не для того, чтобы показать, где они в данный момент, но стараясь привлечь большую аудиторию или отстроить алгоритм поисковой машины на потенциально интересную аудиторию. В 2020 г. сеть Instagram ввела дополнительную опцию сторис - «Близкие друзья". Это возможность добавить часть пользователей в отдельную группу и показывать им предположительно более личный "теплый" контент. Однако практически сразу же опция была активно подхвачена для "прогрева" аудитории, привлечения пользователей в "близкие друзья", например за ряд выполненных пользователями заданий или напрямую за дополнительную оплату.

Итак, обобщая разные подходы к определению культурных индустрий, можно выявить нечто общее, объединяющее акторов в разных сферах: капитализация проекта (некоторого предложения или самой знаменитости) и создание культурной ценности. Мы уже говорили о важности конвертации одного типа капитала в другой: знаний, навыков, создаваемых объектов (культурный капитал) в финансовый эквивалент, определяемый в ходе организации коммуникативного взаимодействия. Или альтернативное достижение равных возможностей путем покупки или благодаря использованию личных связей (социальный капитал). Таким образом, финансовый капитал - важный, но не единственный показатель экономической состоятельности и успешности. Выстраивание социальных связей может принести ощутимые дивиденды и напрямую сказываться на финансовом благополучии субъекта или проекта.

Феномен селебрити буквально собирает три логики капитализации воедино. Селебрити является носителем большого количества слабых связей [Грановеттер, 2009], за счет чего обеспечивает широкий отклик на публикуемую информацию. Для того чтобы стать частью бизнес-стратегии, показатели известности должны обрести считываемые показатели KPI, и мы видим, как фактически каждый элемент медиаплатформы, на которой пользователь выстраивает свой профиль, начинает использоваться для подтверждения социальной и авторитетной статичности героя. Даже если изначально эти показатели задумывались как знаки сближения коммуникативных и эмоциональных аспектов онлайн-среды с привычной повседневностью. Так, лайки, количество друзей, реакции, ответы и реакции на сторис, группы близких друзей, количество комментариев выполняют не только первичную функцию общения, но и вторичную (а для бизнес-стратегии основную) - подтверждения и повышения статуса селебрити. Мы видим, как понятие знаменитости, или селебрити, переходит из области титула, порождаемого зрительским интересом, к статусу, имеющему свои показатели выражения и инструменты достижения, доступные более широкому кругу участников, нежели игроки классических медиа.

Еще один важный принцип, определяющий развитие культуры селебрити в социальных сетях (в особенности Instagram и TikTok), заключается в отношении к авторскому праву и уникальному контенту. Вопрос авторских прав - один из самых острых в сфере культурных индустрий [Davies, Sigthorsson, 2013]. Однако в случае соцсетей мы видим настоящую охоту за реинсценировкой удачных сюжетов. Например, скандальный ролик, в котором рэп-исполнительница Инстасамка выгоняет опоздавших к ней визажистов, а затем сжигает их деньги (февраль 
2021 г.), буквально за следующие сутки инсценировали десятки раз (притом что и сам сюжет Инстасамки тоже был структурно скопирован). Сеть TikTok задала тренд точного воспроизведения некоторого сценария или хореографии под определенную музыку. Авторское право, оригинальность, уникальность отходят на второй план. Перед исследователями феномена встает вопрос секрета популярности и возвышения того или иного пользователя в условиях, когда он может не производить эксклюзивного материала в привычном смысле слова, но привносит некую индивидуальность в уже известный и многократно повторяемый сценарий.

Итак, культура "звезд" становится одним из ключевых элементов культурных индустрий - это система, позволяющая представить некоторый проект или продвинуть ту или иную идею. Развитие отношений «звезда - аудитория" напрямую зависит от технологий медиа. Традиционные медиа задавали систему вертикальной иерархической коммуникации, которая с развитием интернет-платформ трансформируется, создает довольно причудливую структуру, где по-прежнему есть запрос на вертикаль и силу влияния, но необходимо отвечать требованиям горизонтальной прямой коммуникации, вступать в отношения прямого взаимодействия с аудиторией, отвечать трендам новой искренности, соотносить свои высказывания с дискурсами политкорректности, толерантности и т. д.

\section{Селебрити из-за кулис и расширение профессионального поля: от системы звезд к индустрии производства известности}

В классической работе о самопрезентации американского социолога Ирвинга Гофмана была представлена концепция публичного проявления и позиционирования, в основе которой лежит метафора сцены и актерского искусства [Гофман, 2000: 256-275]. Ситуации публичного взаимодействия имеют некий сценарий, участники разыгрывают определенные роли, видят друг друга в предложенных обстоятельствах. От понимания правил и ожиданий во многом зависит успех предложения и позиционирования. Успех самопрезентации заключается в последовательном соблюдении участниками нескольких общих принципов: драматургической верности, дисциплины и последовательности [там же: 256]. Драматургическая верность предполагает, что все участники разыгрываемой сцены разыгрывают общую историю, принимают на себя определенные моральные обязательства и соответствуют ролям и амплуа. Крайне важно, чтобы информация, детали, секреты не уходили "с внутренней кухни", а зритель видел лишь конечный "презентационный" готовый вариант.

Как с этим принципом соотносятся современные практики представления контента? Сегодня публикация так называемых “бэкстейдж»-материалов (того, что не вошло в основную версию, процесс подготовки, работы, кадр за пределами видимого зрителем кадра) - важный источник информации и интереса. Дополнительные материалы становятся фактически основой развития трансмедийного потенциала проектов. Следуя логике описания трансмедийного сторителлинга Генри Дженкинса ${ }^{2}$, история должна быть не просто представлена на платформах разных медиа, но давать заинтересованному зрителю больше опыта, уникального

\footnotetext{
2 Jenkins H. Transmedia Storytelling 101. URL: http://henryjenkins.org/blog/2007/03/transmedia_storytelling_101. html (дата обращения: 01.11.2021).
} 
для каждой площадки. С точки зрения развития культуры селебрити это задает отдельное направление, в корне меняющее логику презентации. Отныне героями становятся не только и не столько главные лица проекта (ведущие актеры, солисты, примы), но и шире - все участники на сцене (актеры второго плана, эпизодических ролей), а затем и члены команды, традиционно остающиеся за кадром - фотограф, оператор, звукорежиссер и др. Все они - полноправные герои представления проекта, они рассказывают свои истории, показывают не парадную картинку, но некий более "честный" и объемный взгляд на процесс. Это вызывает интерес зрителей. Культурные индустрии отвечают на этот интерес разработкой жанровых канонов направления, которое можно условно назвать "фильм о фильме». Документальный жанр, предполагающий, что после выхода значимого культурного текста (в широком понимании слова "текст") последуют дополнительные материалы, где участники расскажут и покажут, как создавался шедевр. Мы видим подобный прием от успешных кинопроектов (фильм о съемках "Игры престолов" или "Аббатства Даунтон") до фильмов, описывающих съемки известных клипов. Подобная стратегия автоматически создает эффект значимости и вовлекает в орбиту зрительского интереса больше участников. Кстати, неслучайно этот прием был насмешливо использован создателями фильма "This is Spinal Tар" (1984), где зритель смотрел классический документальный фильм о легендарной музыкальной группе "Spinal Tap», которую создатели фильма на самом деле изобрели, а в своем мокьюментари лишь обнажили приемы, делающие продукт Шедевром, а участников Героями.

Если же посмотреть на продолжение этих принципов у селебрити эпохи социальных сетей, мы видим, что преодоление принципа драматургической верности расширяет потенциал для создания контента, что принципиально для любого блогера. При этом соблюдается один из главных принципов сетевой культуры эпохи веб 2.0 - приоритет бета-версии над конечной. Этот же принцип поддерживает одна из популярных сегодня моделей управления - Agile, когда для успешной реализации идеи нужно демонстрировать принцип непрерывного развития, обновления, улучшения. С этой точки зрения становится еще более понятной тенденция, изменившая глянцево-приторный образ Instagram-селебрити 2010-х на более откровенные и контрастные истории новых знаменитостей и гуру, демонстрирующих не только стоп-кадры успеха, но и сложный долгий процесс совершенства - от сложностей к достижению. Часто в роли сложностей фигури руют финансовые стесненные обстоятельства, а также лишний вес, депрессия, одиночество и другие трудности. Здесь принцип развития бета-версий, встречаясь с древней архетипической механикой пути героя (в классической работе Дж. Кэмпбелла “Тысячелетний герой») создают коктейль, поддерживающий нужный уровень жажды подробностей у зрителей и включенность аудитории. Процесс создания порой становится интереснее результата.

Расширяется сама среда публичного "видимого", когда в раскрутку и рассказ о событии включаются не только условно классические игроки - перформеры и творцы (артисты, музыканты, режиссеры), но и некогда закулисные участники все те, кто до сих пор был за кулисами или в массовке. Они включаются в систему публичного предъявления себя аудитории как собственными силами (посредством личных страниц), так и посредством других участников медиасреды: журнали- 
стов, рекламщиков, относящихся к такого рода участникам, как к полноценным "классическим" звездам с соответствующими атрибутами: публичным интересом, интервью, рекламными предложениями и т.д.

Помимо включения "закадровой" реальности в формат интересующих зрителя повседневных подробностей, второй частый способ нарушения драматургической верности связан с информационными "сливами", когда слухи, скандальные подробности частной жизни становятся объектом зрительского внимания. С одной стороны, это классический принцип “желтой прессы", который лишь меняет площадки от бумажных газет к Telegram-каналам и Instagram-аккаунтам. Но для развития культуры селебрити важно, что скандал или "экспертность" в области комментариев к какой-то острой теме могут стать самостоятельной стратегией раскрутки персоны. Так, скандальное расставание певицы Ольги Бузовой с певцом Давой было столь активно распространено пресс-аккаунтами и аккаунтами самих участников в соцсетях, что не только привлекало внимание к событиям и уже известным персонам, но и обеспечило существенный прирост аудитории и внимания ко всем участникам конфликта - и к более пулярным, и к молодому, не столь известному широкой аудитории.

Второй принцип успешной презентации, который И. Гофман называет драматургической дисциплиной, связан с последовательностью, сосредоточенностью на возможностях и ограничениях ролей и полномочий, которым должен следовать каждый участник спектакля публичности. Исполнитель должен помнить свою роль и не допускать при исполнении непроизвольных жестов и провалов. Про провалы и непроизвольные жесты мы поговорили чуть выше - ошибка, провал, откат могут стать прекрасным источником для создания разнообразного контента, показывающего путь развития. А вот принцип соответствия роли, кажется, требует особого внимания. В мае 2019 г. на ҮouTube-канале Ксении Собчак вышел эфир авторского шоу, получивший название «Инстаграмщицы. Высший свет против девушек в купальниках", собравший на сегодняшний день почти 5 млн просмотров ${ }^{3}$. Это весьма показательная для нашего разговора дискуссия о заслуженности славы и признания (в том числе финансового) новых Instagram-селебрити, за которыми не стоит ни первоначальных свершений, как за классическими звездами, ни финансовой или профессиональной топ-позиции. В программе героини, называемые "тяжелым люксом" - состоятельные дамы, клиентки дорогих бутиков, способные в повседневной жизни поддерживать самый высокий уровень потребления (при этом сами они необязательно претендуют на публичный статус), говорят, как оскорблены тем, что серьезные компании охотно предоставляют свою продукцию и преференции девушкам с успешно развиваемыми Instagram-аккаунтами. Выпуск шоу интересен тем, насколько остро в нем обнаруживается внутренний конфликт, по сути девальвирующий понятие звездности в контексте современного дискурса селебрити. Продуманная бизнес-стратегия раскрутки и соответствие некоторому неуникальному параметру, например параметрам фигуры, становится достаточным основанием в битве за приобретение статуса инфлюенсера, а это в свою очередь ведет к получению привилегий селебрити, а затем уже открывает двери и к другим

\footnotetext{
3 ИНСТАГРАМЩИЦЫ I Высший свет против девушек в купальниках. URL: https://www.youtube.com/watch?v=5LP3q 6Pb_8Q\&t=1414s (дата обращения: 30.10.2021).
} 
аспектам жизни селебрити - будь то круг потребительских возможностей или коммуникативных проявлений, таких как интервью, приглашения, съемки и т.д.

Наконец, третий принцип успешной презентации Гофмана связан с осмотрительностью. "Когда велика вероятность подвергнуться контрольной проверке, неприкрашенные факты можно представлять другим в радужном свете, и исполнители могут играть свою партию во всю силу, демонстрируя все свои достоинства" [Гофман, 2000: 262]. Внеплановая проверка и потенциальная возможность обнародовать любую частную конфликтную ситуацию-одна из ключевых черт современного медиаландшафта. Кричащие на уроке учителя, конфликты на работе, несоответствие нормам и требованиям безопасности - формат шоу-ревизоров стал одной из популярных логик развития контента, заведомо потенциально востребованного у широкой аудитории.

Итак, тесное переплетение зрительских ожиданий, форматов классического телевидения и жанров профессиональной прессы встречается в социальных сетях с возможностью бесконечного расширения числа участников, претендующих на ведущую роль. Борьба за аудиторию - не только следствие тщеславия участников, но и необходимое условие развития любого проекта, продукта и индустрии. Закадровые съемки и участники "из-за кулис" становятся новыми источниками внимания и интереса. Бывшие в тени ведущих исполнителей, с развитием новых медиа участники профессионального поля получают право заявить о себе. Это может быть важным шагом в развитии карьеры и формировании персонального бренда. Как, например, фотограф Дмитрий Марков, чьи фотографии вышли за пределы Instagram, обеспечили ему широкую профессиональную известность, а затем и интерес к персоне (приглашение на интервью, приглашение в качестве ведущего программы, публичные высказывания по несвязанным с фотографией темам). Марков стал героем сразу нескольких рейтинговых каналов на YouTube - c ним выходили интервью на каналах “Редакция" и "вДудь». Сегодня Марков не только известный фотограф, но и ведущий собственной программы в проекте канала "Редакция", на его персональный аккаунт в Instagram подписано более 800 тыс. пользователей.

В первой части статьи мы говорили о том, как понятие "селебрити" трансформируется, вовлекая в свою орбиту большее количество участников, вырабатывая определенные алгоритмы соответствия, разворачивая жесткую конкуренцию за внимание зрителей между тысячами участников. Расширение репертуара ролевых моделей вкупе с закреплением повторяющихся приемов повествования и репрезентации приводит к важному сдвигу в понимании сути селебрити (и микроселебрити). Споры о значимости влияния персоны, которые получают числовые статистические данные рейтингов внимания и реакций, становятся скорее рабочей информацией для расчета маркетинговых кампаний, но не имеют абсолютных величин соответствия для всех ниш. Само же понятие "селебрити" сдвигается в своем значении скорее к набору правил поведения и персональной репрезентации - способов показывать себя, снимать истории, задавать темы обсуждений, общения с аудиторией и т.д.

Внимание к традиционным областям шоу-бизнеса с развитием социальных сетей дополнилось другими темами, расширяя репертуар ролей и профессио- 
нальных ниш, которые интересны аудитории и участники которых вовлекаются в освоение общих принципов производства собственного образа в канонах культуры знаменитостей.

Классические медиа изредка разнообразили пространство героями-звездами из неартистической среды. Можно вспомнить несколько имен «академических звезд" на телевидении - таких как Маршалл Маклюэн, активно включенный не только в изучение, но и самопрезентацию на телевидении. Мы можем привести ряд программ, популяризирующих науку и сделавших настоящими селебрити своих ведущих. Например, Николая Дроздова, профессора МГУ и ведущего одной из классических телепрограмм еще советского телевидения "В мире животных". Как мы уже отметили, культура селебрити - это в первую очередь медиатизированная культура, и классические медиа создают дефицитную модель, при которой ограниченный ресурс трансляции формирует повышенный спрос и статус тому, кто все же пробился через узкий фильтр к аудитории.

Изменения новых медиа, о которых мы говорили выше, приводят к расширению возможностей заявить о себе, а вместе с этим и к расширению бизнес-стратегий продвижения товаров, услуг самого разного толка. Раз производство публичной личности-бренда можно определить как некоторую технологию, разработанную специалистами в области коммуникаций и культурных индустрий, очевидно, что расширение медиавозможностей приведет к повышению запроса на производство селебрити в разных областях и сферах жизни. Быть известным, быть востребованным в классическом медиаполе (выступать на телевидении, давать интервью), проводить встречи с поклонниками и собирать залы. Писать книги и раздавать автографы. Размещать профессиональные фотосессии. Отныне это не мечта начинающих артистов, но и повседневный труд врачей, учителей, психологов, репетиторов, мастеров и всех тех, кто развивает свой бизнес в самых разных областях, далеких от шоу-бизнеса. Это существенно меняет и трансформирует профессиональные повседневные практики экспертов, вносит новые требования и формирует запрос на развитие дополнительных гибких навыков. Это косвенно подтверждает высокий спрос на услуги тренеров речи и дикции, фотопозирования и раскрепощения, съемок и монтажа видео, копирайта. Сегодня для того, чтобы быть преуспевающим специалистом в своей области (особенно если ты работаешь на себя), необходимо включить в практики производства и собственный публичный имидж.

Мы проанализировали 30 блогов русскоязычных экспертов помогающих профессий (доктора, психологи, репетиторы - в равных пропорциях) с аудиторией более 10000 подписчиков. Этот небольшой срез мы использовали для фокуса внимания на самых общих тенденциях. Дальнейшее изучение темы и описание частных особенностей позиционирования потребует, безусловно, исследования на большей выборке. Территориальную привязку блогов описать представляется затруднительным, так как место нахождения либо непринципиально самому блогеру и он не акцентирует его в материалах либо сознательно меняет геолокации от сообщения к сообщению. Обобщая основные тенденции и приемы, можно выделить следующее:

1. Все пользователи в своей контент-политике чередуют исключительно профессиональную информацию с презентацией определенных аспектов своей 
частной жизни - отношений в семье, увлечений, отдыха и т.д. С одной стороны, это продиктовано запросом на постоянную сетевую активность и обновление контента. Но, с другой стороны, в этом можно усмотреть и стремление повторить путь "больших звезд", чья частная жизнь является темой пристального зрительского внимания.

2. Проведение профессиональных фотосессий и использование сессионных фотографий в оформлении аккаунтов становится важной частью блогов. Здесь мы сталкиваемся еще с одной проблемой селебрити не из мира шоу-бизнеса: эксперты, чья жизнь предполагает по роду деятельности более рутинизированные практики, испытывают сложности с созданием постоянно обновляемого визуально контента.

3. Еще одна общая черта - демонстрация экспертности шире основной предлагаемой услуги. Темы профессиональных предложений (курсы, тренинги, консультации и т.д.) чередуются с более цельным освещением области занятости и нередко подкрепляются дополнительными активностями, такими как выпуск книг, фан-встречи с аудиторией и др. Здесь оказываются востребованы регалии и рассказы о профессиональных достижениях. Часто они повторяются регулярно или подаются в виде серии постов "Моя история", "История становления". Особое место в системе позиционирования отводится опыту внешней медиавостребованности - участию в качестве приглашенного эксперта в телевизионных проектах, интервью, гостевые визиты на другие каналы. Подобного рода опыт подтверждает высокий статус и значимость персоны. Использование общих принципов раскрутки аккаунтов: перекрестные эфиры, акции, конкурсы и другие формы деятельности, способствующие вовлечению аудитории и повышению “видимости" эксперта в публичном пространстве. Новые возможности позиционирования создают не только новые возможности расширения аудитории, но и жесткую конкурентную среду, которая требует от участников быстрого освоения большого круга дополнительных компетенций или формирования собственной команды.

\section{Заключение}

Мы рассмотрели несколько понятий, описывающих публично известных персон (селебрити, знаменитости, инфлюенсеры) в контексте влияния развития медийных технологий на способы позиционирования и интерес со стороны аудитории. Технологические и коммуникативные изменения в сфере новых медиа привели к существенному расширению репертуара ролей, позволяющих привлекать новые голоса и образы в систему селебрити - производить не просто известные аудитории образы, но и оказывающие воздействие. Коммуникация влияния предполагает распространение актуальной повестки дня, рекламного контента, повышение трансмедийного потенциала больших медиапроектов, появление новых локаций и персонажей активного интереса массовой аудитории, успешное предложение знаний, умений и услуг и т.д. Все больше пользователей социальных сетей используют в своем повседневном общении принципы взаимодействия, ранее характерные для классических “звезд",- автограф-сессии, распространение собственных профессиональных фотосессий, интервью, знакомство с деталями приватной жизни и т. д. При этом важно, что речь идет не столько о случайно 
совпадающих приемах, но о складывающейся системе новых практик, со своими правилами, нормами, новыми профессионалами (smm-специалисты, информационные продюсеры, продюсеры TikTok-домов и другие новые игроки рынка). Отчасти культура селебрити новых медиа базируется на многообразии приемов, открытых телевидением и прессой, но также привносит и собственные решения. Переходя в социальные сети, практики "раскрутки" отдельных персон используют каждый технологический элемент, предлагаемый сетью, для достижения более высоких и исчисляемых знаков успешности - от количества лайков до опций диверсификации аудитории типа "близких друзей". Это, в свою очередь, позволяет повысить социальный и культурный капитал героя с отработанными путями конвертации публичной востребованности в финансовый успех или вовлечение аудитории в воронки продаж того или иного продукта/предложения.

Появление новых участников, жесткая конкуренция за внимание, расширение рынков аудитории и участников, освоение рядовыми пользователями практик создания контента и принципов коммуникативных паттернов общения с аудиторией приводят к важному сдвигу в понимании сути понятия "селебрити" (и "микроселебрити"). Культура и дискурс селебрити сегодня - это не только (а порой и не столько) степень известности, подтвержденная статистикой зрительских охватов, вовлеченностью аудитории, перекрестным информационным шумом, но в большей степени набор действий (количество историй, наличие профессиональных фотосессий, интервью, как бы внешних "кадров папарацци" и т.д.), стиль общения с аудиторией (эфиры, разборы, личные встречи, автограф-сессии, вопросы-ответы и пр.), способы репрезентации собственного образа и чередование определенных рубрик, производящих рассказ о пути становления, сфере профессиональной и повседневной жизни. И если с 1920-х годов расцвет системы звезд был связан с развитием культурных индустрий, медиатехнологий и массовой культуры, то век спустя практики продвижения публичных фигур не только приобрели новые формы и инструменты, но фактически трансформировали объем и наполнение понятия "селебрити". Акцент сместился от привлекающих внимание завоеваний (ролей, хитов, скандалов), освещаемых немногочисленными и усиливающими эффект значимости медиа, к рутинизированным технологиям исполнения "селебрити"-ритуалов. Эти практики известны исполнителям и ожидаемы аудиторией. Приемы и жанры достаточно универсальны для разных сфер и могут вначале создать образ "звезды", а затем представить вниманию "разогретой» аудитории проект-завоевание (встречу, песню, книгу или что-либо), существенно повысив его символический капитал. Селебрити перестали быть только частью культурных индустрий и шоу-бизнеса, но привнесли их элементы в другие области деятельности, став универсальной технологией производства ценности.

\section{Список литературы (References)}

Адорно Т., Хоркхаймер М. Культурная индустрия. Просвещение как способ обмана масс. М.: Ад маргинем, 2016.

Adorno Th., Horkheimer M. (2016) Kulturindustrie - Aufklärung als Massenbetrug. Moscow: Ad marginem. (In Russ.) 
Бурдье П. Формы капитала // Экономическая социология. 2002. № 5. С. 60-75. Bourdieu P. (2002) Formes de capital. Economic Sociology. No. 5. P. 60-75. (In Russ.)

Гофман И. Представляя себя другим в повседневной жизни. М.: Канон-Пресс-Ц: Кучково поле, 2000.

Goffman E. (2000) The Presentation Self in Every Day Life. Moscow: Kanon-Press-Ts; Kuchkovo pole. (In Russ.)

Грановеттер М. Сила слабых связей // Экономическая социология. 2009. № 4. C. $31-51$.

Granovetter M. (2009) The Strength of Weak Ties. Economic Sociology. No. 4. P. 3151. (In Russ.)

Маклюэн М. Понимание медиа: внешние расширения человека. М. : Канон-Пресс-Ц: Кучково поле, 2003.

McLuhan M. (2003) Understanding Media: The Extensions of Man. Moscow: KanonPress-Ts; Kuchkovo pole. (In Russ.)

Маршалл Д. Продвижение и предъявление себя: селебрити как символ презентационный медиа // Логос. 2016. № 6. С. 137-160.

Marshall D. (2016) The Promotion and Presentation of the Self: The Celebrity as a Marker of Presentational Media. Logos. No. 6. P. 137-160. (In Russ.)

Ортега-и-Гассет Х. Восстание масс. М.: АСТ, 2002.

Ortega y Gasset J. (2002) La rebelión de las masas. Moscow: AST. (In Russ.)

Тросби Д. Экономика и культура. М. : Издательский дом ВШЭ, 2013.

Throsby D. (2013) Economics and Culture. Moscow: HSE Publ. House. (In Russ.)

Хестанов Р. Креативные индустрии - модели развития //Социологическое обозрение. 2018. № 3. C. 173-196. https://www.doi.org/10.17323/1728-192X-2018-3-173-196. Khestanov R. (2018) Creative Industries - Models of Development. Russian Sociological Review. No. 3. P. 173-196. https://www.doi.org/10.17323/1728-192X-20183-173-196. (In Russ.)

Austin T., Barker M. (2003) Contemporary Hollywood Stardom. New York, NY: Oxford University Press.

Banks M. (2019) Valuing Cultural Industries. London: Routledge.

Davies R., Sigthorsson G. (2013) Introducing the Creative Industries: From Theory to Practice. Los Angeles: Sage.

Evans J. (2005) Celebrity, Media and History. Understanding Media: Inside Celebrity. New York, NY: Open University Press. P. 11-57.

Giles D. (2018) Twenty-First Century Celebrity. Fame in Digital Culture. London: Emerald. Lazarsfeld P., Berelson B., Gaudet H. (1944) The People's Choice. How the Voter Makes up His Mind in a Presidential Campaign. New York, N.Y.: Duell, Sloan, and Pearce.

Marwick A. (2013) Status Update. Celebrity, Publicity, and Branding in the Social Media Age. New Haven, CO: Yale University Press. 